\title{
Root-lesion and root-knot nematodes parasitizing potato
}

\author{
Ivânia Esteves • Carla Maleita • Isabel Abrantes
}

Accepted: 7 October 2014 / Published online: 18 October 2014

(C) Koninklijke Nederlandse Planteziektenkundige Vereniging 2014

\begin{abstract}
Root-lesion nematodes (RLN), Pratylenchus spp., are economically important plant-parasitic nematodes (PPN) of several crops, including potato. In Portugal, potato cyst nematodes (PCN), Globodera spp., are a frequent problem and root-knot nematodes (RKN), Meloidogyne spp., have been found coexisting with PCN. Although the diversity and pathogenicity of PCN on potato are well documented, little work has been done to evaluate the importance of other PPN. This study aimed at assessing the diversity of RLN and RKN in potato. Sampling encompassed fields located in four regions of Portugal: North, Centre, Lisboa and Algarve. Nematodes were extracted from 40 soil/root samples, using standard extraction techniques, identified at genus level and population densities quantified. RLN species were identified on basis of morphological characters, species specific primers, and D2D3 28S rDNA sequencing. RKN and PCN species were identified by esterase phenotype and PCR-RFLP, respectively. RLN were detected in all sampled regions in $83 \%$ of soil and $78 \%$ of root samples. Pratylenchus penetrans was the most abundant species and $P$. neglectus, $P$. crenatus and P. thornei were detected for the first time associated with potato in Portugal. Meloidogyne arenaria, M. hapla, M. incognita and M. javanica were found in $10 \%$ of soil and $20 \%$ of roots. Globodera pallida and G. rostochiensis were detected in 15 and $8 \%$ of soil and
\end{abstract}

I. Esteves $(\bowtie) \cdot$ I. Abrantes

IMAR-CMA, Department of Life Sciences, University of Coimbra, 3004517 Coimbra, Portugal

e-mail: ivaniaesteves@yahoo.com

C. Maleita

CIEPQPF, Department of Chemical Engineering, University of Coimbra, 3030790 Coimbra, Portugal roots. RKN and PCN were found in samples infected with RLN. The information obtained on the ubiquity and diversity of RLN and RKN reinforces the need for a careful monitoring of these nematodes in potato crops.

Keywords Meloidogyne P Portugal P Pratylenchus . Ribosomal DNA · Solanum tuberosum

\section{Introduction}

Root-lesion nematodes (RLN), Pratylenchus spp., are serious pests, causing damage in a wide range of cultivated plants, including potato, Solanum tuberosum. As migratory endoparasites, RLN differ from other important root parasites as they enter and leave roots during their life cycle, move actively through soil and penetrate the root for feeding and reproduction. Common symptoms associated to these nematodes on potato plants include reduced growth, occasional yellowing of the foliage and severe necrosis in roots and tubers (Castillo and Vovlas 2007). The wide host range of RLN limits the use of crop rotation to manage these nematodes, which enhance the risk of increasing their population densities. Moreover, infection by RLN can favour the entrance of other plant pathogens such as the soil-borne fungus Verticillium dahliae, involved in the potato early-dying disease complex (Rowe et al. 1985).

Populations of $P$. alleni, P. crenatus, $P$. neglectus, P. penetrans, $P$. scribneri and $P$. thornei have been found associated with poor growth of potato plants in several production areas (Castillo and Vovlas 2007). Other RLN species, such as $P$. brachyurus, $P$. coffeae, $P$. vulnus and $P$. flakkensis, are also known to damage potatoes in 
tropical regions (Jatala and Bridge 1990). In Europe, RLN were detected in $61 \%$ of the soil samples taken from poorly growing patches of potato in a field survey in The Netherlands. Five Pratylenchus species were identified being $P$. neglectus the most abundant and $P$. penetrans the most aggressive (Van Der Sommen et al. 2009). In addition, RLN were found coexisting with potato cyst nematodes (PCN), Globodera spp. (Van Der Sommen et al. 2009). In Norway, routine potato soil sampling, from a field where an oval patch of poor growth was observed, showed large numbers of $P$. penetrans and negative results for PCN (Holgado et al. 2009). In Portugal, an average of 25000 ha of potatoes are grown every year (Instituto Nacional de Estatística 2013). The average potato yield is around $17 \mathrm{t} / \mathrm{ha}$ in Portugal, compared to $30 \mathrm{t} / \mathrm{ha}$ in the EU (FAOSTAT 2012). Such difference in yield is attributed, to a great extent, to the presence of $\mathrm{PCN}$, which occurs in all main potato production areas, with a national average of $50 \%$ of fields infested and $100 \%$ in some areas (Cunha et al. 2004). However, these nematodes might not be the only plant-parasitic nematodes (PPN) responsible for low potato yields. Although the diversity and pathogenicity of PCN is well documented (Santos et al. 1995; Cunha et al. 2004, 2012) that of RLN have received little attention. A single record identified $P$. penetrans in potato soil and roots collected in Monchique, Algarve (Abrantes et al. 1987).

Pratylenchus species can be identified by means of morphological and morphometric characters (CarrascoBallesteros et al. 2007), but needs expertise since most specific differences can only be observed using high magnifications (Castillo and Vovlas 2007). Considering the potential impact of RLN in potato fields, identification of these nematodes to the species level, is essential and DNA-based methods provide efficient and reliable tools (Uehara et al. 1998; Waeyenberge et al. 2000; AlBanna et al. 2004; Yan et al. 2008). The 28S D2D3 expansion fragments of ribosomal DNA (rDNA) have been used frequently for RLN identification (De la Peña et al. 2007; Subbotin et al. 2008).

The EU quarantine nematode $M$. chitwoodi and other Meloidogyne species, including M. arenaria, M. hapla, $M$. hispanica, M. incognita and $M$. javanica, have been found in potato fields in Portugal (Conceição et al. 2009). Meloidogyne hispanica showed great aggressiveness to potato cultivars and studies on the thermal requirements, considered $M$. hispanica an emerging RKN species (Maleita et al. 2012a, b).
An accurate identification of PPN is therefore important for quarantine purposes and to define effective and sustainable integrated pest management programmes. So far, little research has been conducted to evaluate the presence of other PPN than PCN in potato and even lesser recent studies included the accurate identification of the RLN species involved. The objectives of this study were: i) to identify the RLN and RKN species and other PPN in potato fields, ii) to assess their diversity, and iii) to increase the knowledge on the importance of RLN and RKN in Portuguese potato fields. Finally, the work aimed to provide information which can be used in a broader perspective allowing comparisons with similar studies within the European context on the occurrence of RLN and RKN in potato crops.

\section{Materials and methods}

Sampling, field history and soil analyses

Soil and root samples were collected in May-June 2012, approximately 2 weeks before potato harvest, from a total of 40 fields located in four of the five regions of Continental Portugal, according to the Nomenclature of Territorial Units for Statistics (NUTS II) (Instituto Nacional de Estatística 2013): North (Porto district), Centre (Aveiro, Castelo Branco, Coimbra, Guarda and Leiria districts), Lisboa (Lisboa and Setúbal districts) and Algarve (Faro district) (Fig. 1). Sampling encompassed the major regions for potato production in Portugal (Santos et al. 1995). Each soil sample consisted of 10-20 sub-samples/ha taken around the root zone at 15$20 \mathrm{~cm}$ depth. Root samples consisted in a mixture of roots taken from 4 to 8 potato plants, at each site. Soil and root samples were placed into separate polyethylene bags, stored at $4{ }^{\circ} \mathrm{C}$ and processed within 3 days. The potato cultivars most commonly planted were 'Agria', 'Astérix', 'Kennebec' and 'Picasso'. No nematicide or supplementary irrigation was applied in any of the fields sampled. Maize or beans were used in rotation with potato, or a fallowing period followed the potato crop. Soil analyses for $\mathrm{pH}$, organic matter and available phosphorus and potassium were determined at the Laboratory of Soils and Fertility, Higher School of Agriculture, Coimbra, Portugal. 
Fig. 1 Location of sampling districts in each region, according to the Nomenclature of Territorial Units for Statistics (NUTS II)

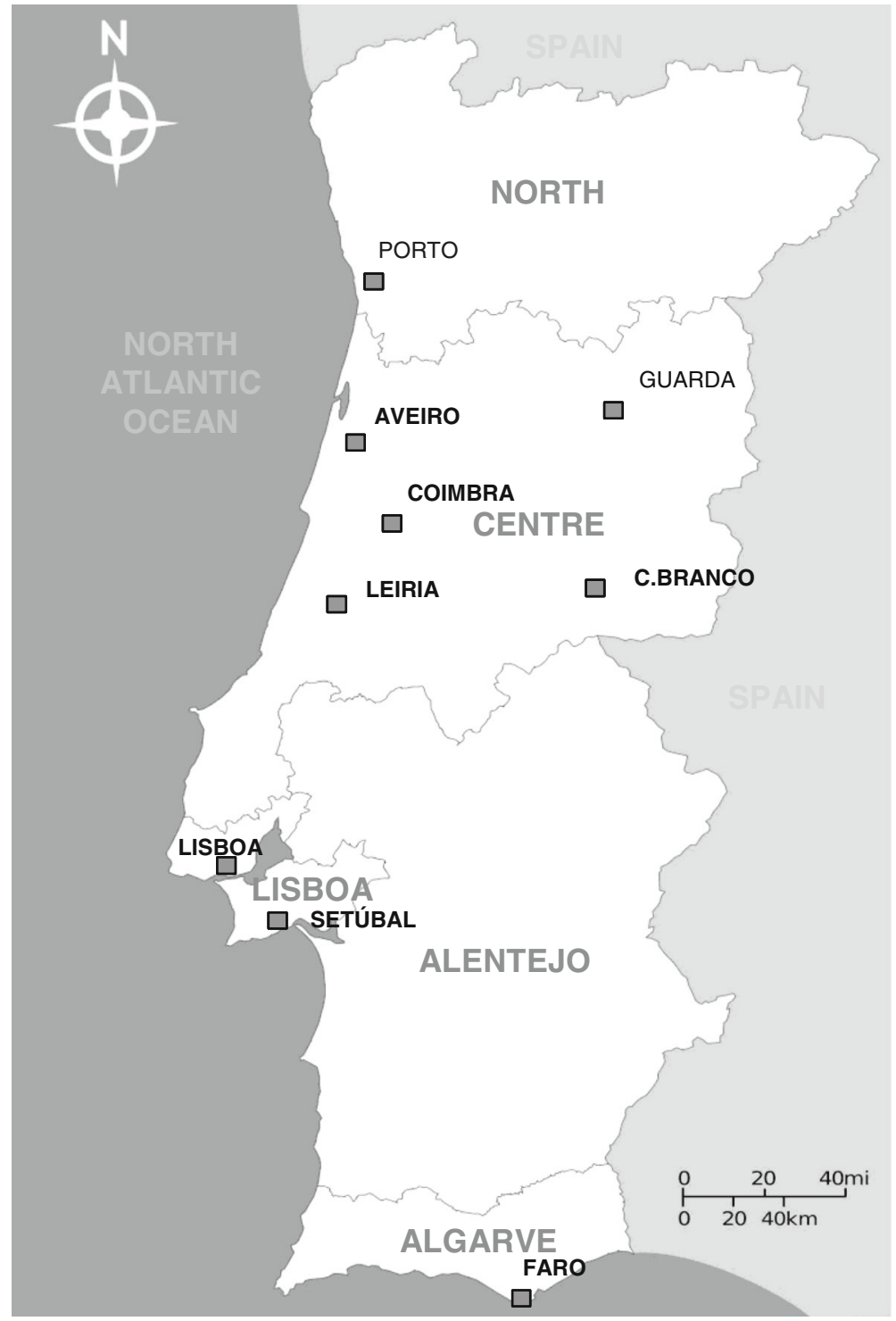

Extraction and quantification of plant-parasitic nematodes from soil and roots

Nematodes were extracted from soil according the generalist Tray Method (Whitehead and Hemming 1965). Soil was sieved using a $4.5-\mathrm{mm}$ sieve to remove root fragments and $200 \mathrm{~g}$ of soil poured evenly onto a Kleenex ${ }^{\circledR}$ tissue sheet on a plastic net, in a plastic tray with water. After $48 \mathrm{~h}$, the nematode suspension was collected by passing the suspension through a $20-\mu \mathrm{m}$ pore size sieve. Nematodes were observed under an inverted stereomicroscope and the PPN identified at genus level. A
$50 \mathrm{~g}$ soil sub-sample was kept aside and ovendried, at $100{ }^{\circ} \mathrm{C}$ for $24 \mathrm{~h}$, to determine soil dry weight that was used to express the population density per $100 \mathrm{~g}$ of dry soil.

Potato roots were gently washed to remove soil debris, and observed under a stereomicroscope for the presence of RKN galls or egg masses, and PCN females or cysts. The Pratylenchus species were extracted from root samples cut in $1 \mathrm{~cm}$ root fragments, using Baermann funnels (Baermann 1917) during 14 days. Numbers of Pratylenchus were counted and expressed per $10 \mathrm{~g}$ of fresh root. Single nematode specimens hand-picked from the 
Table 1 Primers used for molecular identification of root-lesion nematodes, Pratylenchus spp. from root samples collected in potato fields in Continental Portugal

\begin{tabular}{|c|c|c|c|c|}
\hline Primer code & Species & Predicted fragment size (bp) & Primer sequence (5'-3') & Reference \\
\hline $\begin{array}{l}\text { PNEG-F1 } \\
\text { D3B5 }\end{array}$ & P. neglectus & 144 & $\begin{array}{l}\text { CGCAATGAAAGTGAACAATGTC } \\
\text { AGTTCACCATCTTTCGGGTC }\end{array}$ & Yan et al. 2008 \\
\hline $\begin{array}{l}\text { PPEN } \\
\text { D3B }\end{array}$ & P. penetrans & 278 & $\begin{array}{l}\text { TAAAGAATCCGCAAGGATAC } \\
\text { TCGGAAGGAACCAGCTACTA }\end{array}$ & Al-Banna et al. 2004 \\
\hline $\begin{array}{l}\text { PTHO } \\
\text { D3B }\end{array}$ & P. thornei & 288 & $\begin{array}{l}\text { GAAAGTGAAGGTATCCCTCG } \\
\text { TCGGAAGGAACCAGCTACTA }\end{array}$ & Al-Banna et al. 2004 \\
\hline $\begin{array}{l}\mathrm{D} 2 \mathrm{~A} \\
\mathrm{D} 3 \mathrm{~B}\end{array}$ & Pratylenchus spp. & $750-1,100$ & $\begin{array}{l}\text { ACAAGTACCGTGAGGGAAAGTTG } \\
\text { TCGGAAGGAACCAGCTACTA }\end{array}$ & De Leij et al. 1999 \\
\hline
\end{tabular}

suspensions collected from the root samples were used for identification. RLN were identified taking into account the morphometrical diagnostic characters, using a dichotomous key (Castillo and Vovlas 2007). For molecular identification, DNA extraction was performed using DNeasy Blood \& Tissue kit (Qiagen, Hilden, Germany), following the spincolumn protocol for purification of total DNA from animal tissues. The molecular identification was carried out using species specific primer sets for P. neglectus (PNEG-F1/D3B5), P. penetrans (PPEN/D3B) and P. thornei (PTHO/D3B) (AlBanna et al. 2004; Yan et al. 2008) (Table 1). When amplification products were not obtained with the species-specific primers, the D2D3 expansion region of the $28 \mathrm{~S}$ rDNA gene was amplified using D2A and D3B primers and sequenced (De Leij et al. 1999). All PCR reactions $(25 \mu \mathrm{L})$ contained $5 \mu \mathrm{L}$ of DNA template and $0.75 \mathrm{U}$ of BioTaq DNA polymerase (Bioline, Luckenwalde, Germany) in $1 \times$ buffer, $1.5 \mathrm{mM} \mathrm{MgCl}, 200 \mu \mathrm{m}$ dNTPs and $0.5 \mu \mathrm{M}$ of each primer. The amplifications were carried out according to the PCR conditions listed in Table 2. PCR products were separated by electrophoresis in $1.5 \%$ TBE-buffered agarose stained with GreenSafe (Nzytech, Lisboa, Portugal) and visualized under UV light. For sequencing, amplified products of D2D3 region were purified from agarose gels with the QIAquick gel Extraction kit (Qiagen) and sent to Macrogen Europe for nucleotide sequence analysis by standard procedures. The sequences were checked, corrected manually, when necessary, and aligned with the software BioEdit sequence Alignment Editor (Hall 1999). Then, the sequences were compared to nucleotide sequences in the GenBank database using the basic local alignment search (BLAST), to determine the best match for Pratylenchus spp. (Zhang et al. 2000).

RKN egg masses were picked from infected potato roots, and single egg masses were inoculated on tomato cv. Easypeel. Alternatively, when RKN second-stage juveniles were detected in the nematode suspensions obtained from soil samples, the RKN-infested field soil was potted and a tomato seedling transplanted. Two months later, the presence/absence of galls and egg masses in the roots were observed. The RKN isolates were maintained continuously, in a growth chamber at $25 \pm 2{ }^{\circ} \mathrm{C}$, with a photoperiod $12 \mathrm{~h}$, on the susceptible tomato cv. Easypeel by transferring the cultures, every 2 months, to new tomato seedlings, using $10 \mathrm{egg}$ masses/plant placed beneath the tomato roots.

Table 2 Amplification conditions used in the identification of root-lesion nematodes, Pratylenchus spp. from root samples collected in potato fields in Continental Portugal

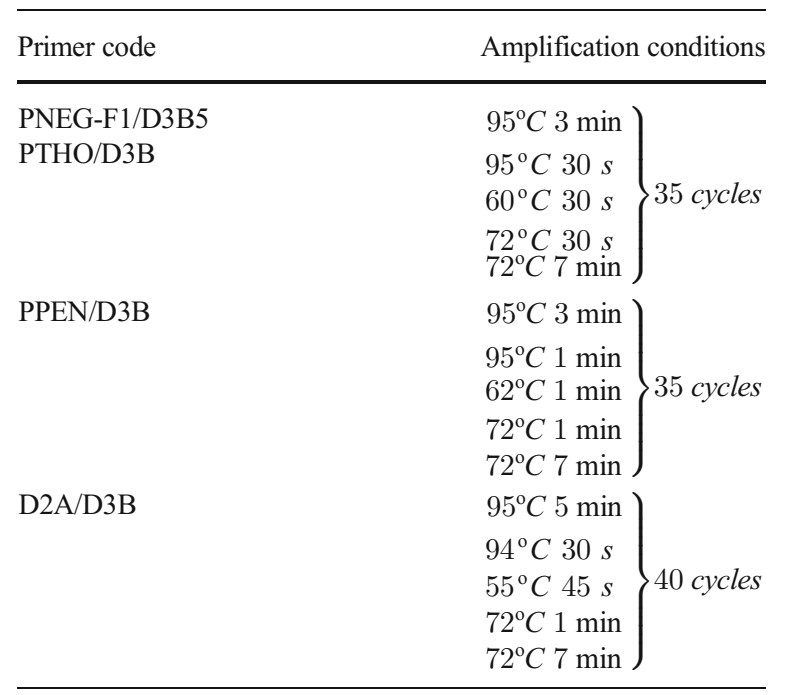


Table 3 Soil properties of the samples collected in potato fields in each district of Continental Portugal

\begin{tabular}{llll}
\hline $\begin{array}{l}\text { NUTS II } \\
\text { District }\end{array}$ & Number of sampling sites & Organic matter $(\%)^{\mathrm{b}}$ & \\
\hline $\begin{array}{l}\text { North } \\
\quad \text { Porto }\end{array}$ & 8 & $3.1 \pm 0.6$ & $4.1 \pm 0.2$ \\
Centre & & & \\
$\quad$ Aveiro & 6 & $2.8 \pm 0.8$ & $5.5 \pm 0.7$ \\
Castelo Branco & 2 & $2.7 \pm 0.3$ & $4.5 \pm 0.7$ \\
Coimbra & 8 & $1.9 \pm 1.0$ & $4.9 \pm 0.7$ \\
$\quad$ Guarda & 2 & $3.6 \pm 2.2$ & $5.7 \pm 1.3$ \\
$\quad$ Leiria & 1 & $2.9 \pm 0.0$ & $5.0 \pm 0.0$ \\
Lisboa & & & $7.5 \pm 0.2$ \\
$\quad$ Lisboa & 5 & $0.7 \pm 0.3$ & $7.4 \pm 0.1$ \\
$\quad$ Setúbal & 3 & $1.8 \pm 0.9$ & $7.0 \pm 0.3$ \\
Algarve & & & \\
$\quad$ Faro & 5 & $1.8 \pm 0.8$ & \\
\hline
\end{tabular}

${ }^{\mathrm{a}}$ Nomenclature of Territorial Units for Statistics

${ }^{\mathrm{b}}$ Data are means of sampling sites \pm standard deviation

Meloidogyne species were identified by the esterase phenotype of the females. Single young egg-laying females from potato roots or five females from each single egg mass isolate maintained on tomato were handpicked and transferred to micro-hematocrit tubes with $5 \mu \mathrm{L}$ of extraction buffer $(20 \% \mathrm{w} / \mathrm{v}$ sucrose with $1 \% \mathrm{v} / \mathrm{v}$ Triton $\mathrm{X}-100)$. The females were macerated with a pestle, frozen and stored at $-20{ }^{\circ} \mathrm{C}$ and the electrophoresis performed according to Pais et al.

Table 4 Plant-parasitic nematodes genera, prevalence and number found in potato soil samples in Continental Portugal

\begin{tabular}{lll}
\hline Genus & $\begin{array}{l}\text { Infested soil samples } \\
(\%)\end{array}$ & $\begin{array}{l}\text { Nematodes/100 g } \\
\text { soil }^{\mathrm{a}}\end{array}$ \\
\hline $\begin{array}{l}\text { Tylenchus } \text { s.1. } \\
\text { Pratylenchus }\end{array}$ & 95 & $39 \pm 60(1-283)$ \\
Tylenchorynchus & 65 & $52 \pm 94(2-456)$ \\
$\quad$ s.l. & & $35 \pm 39(5-179)$ \\
Rotylenchus & 25 & $25 \pm 28(5-85)$ \\
Helicotylenchus & 20 & $21 \pm 17(3-55)$ \\
Globodera & 15 & $12 \pm 13(2-30)$ \\
Meloidogyne & 10 & $53 \pm 88(5-185)$ \\
Hemicycliophora & 5 & $34 \pm 6(30-37)$ \\
Paratylenchus & 3 & $8 \pm 9(2-15)$ \\
\hline
\end{tabular}

${ }^{a}$ Data are means of samples/sampling site \pm standard deviation (range)
(1986). The gels were stained for esterase activity with the substrate $\alpha$-naphthyl acetate (Sigma, St. Louis, USA). Protein extracts of $M$. javanica were included in each gel as a reference.

To identify the Globodera species, cysts were removed from potato roots, and the DNA extracted, as referred before, was processed by PCR-RFLP diagnostic method (Sirca et al. 2010).

\section{Results}

Soil analyses

The percentage of organic matter was low in all samples (Table 3) and, in general, soils were sandy soils (data not shown). The lowest organic matter content was found in soils collected in Lisboa district $(0.7 \%)$; the highest content in samples from Guarda, Centre (3.6 \%). Soils collected in North (Porto) and Centre regions (Aveiro, Guarda, Castelo Branco, Coimbra and Leiria) had low $\mathrm{pH}$ values (4.1-5.7), whereas the $\mathrm{pH}$ of soils in Lisboa, Setúbal (Lisboa) and Faro (Algarve) ranged from neutral to slightly alkaline (7.0-7.5). High concentrations $(>200 \mathrm{mg} / \mathrm{kg})$ of available phosphorous 
$\left(\mathrm{P}_{2} \mathrm{O}_{5}\right)$ and potassium $\left(\mathrm{K}_{2} \mathrm{O}\right)$ were detected in all analysed samples (data not shown).

Plant-parasitic nematodes from soil samples

Plant-parasitic nematodes were detected in soil samples from all regions and they belonged to nine different genera (Table 4): Tylenchus s.l., found in the majority of soils (95 \%), Pratylenchus, Tylenchorynchus s.1., Rotylenchus, Helicotylenchus, Globodera, Meloidogyne, Hemicycliophora and Paratylenchus. Nevertheless the most abundant nematodes belonged to the genera

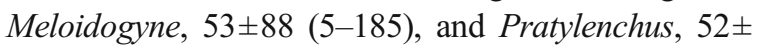
94 (2-456) (Table 4).

The average RLN population densities varied, from 9 to 160 nematodes/100 $\mathrm{g}$ soil (Table 5). Variation in RLN densities were found in samples collected within the same sampling district. In three samples from Porto (North), the densities surpassed the 225 nematodes/100 g soil while in the other five, densities were below 100 nematodes/100 g soil (data not shown). Average densities lower than 26 nematodes/100 g soil were found in all districts, except Porto district (Table 5).
Identification of plant-parasitic nematodes from root samples

Root-lesion nematodes were detected in $78 \%$ of the potato root samples (31 samples). The percentage of fields infected varied from $0 \%$ in Lisboa district (Lisboa) to $100 \%$ in Porto (North), Aveiro, Castelo Branco, Leiria (Centre) and Setúbal (Lisboa) and the average population densities ranged from 6 to 1,301 nematodes/10 $\mathrm{g}$ fresh root (Faro and Porto, respectively) (Table 5). Molecular identification with species-specific primers and sequencing confirmed the morphological identification of $P$. penetrans, $P$. neglectus, $P$. thornei and $P$. crenatus. The PCR products amplified, using species-specific primer sets for $P$. penetrans, $P$. neglectus, and $P$. thornei, are shown in Fig. 2. The P. penetrans primer set PPEN/D3B amplified a unique PCR product of ca. 280 bp in 13 out of 31 samples (42\%). Likewise, an amplification product of ca. $140 \mathrm{bp}$ was obtained in 11 (35\%) other samples using the primer set PNEG/D3B5 for $P$. neglectus and the $P$. thornei primer set $\mathrm{PTHO} / \mathrm{D} 3 \mathrm{~B}$ yielded a $\mathrm{PCR}$ product of ca. 290 bp in two samples (3\%). In a sample from Coimbra (Centre), DNA extracted separately from single nematodes either amplified $P$. penetrans or P. thornei.

Table 5 Prevalence and number of Pratylenchus spp. found in potato soil and root samples at each district of Continental Portugal

\begin{tabular}{|c|c|c|c|c|}
\hline $\begin{array}{l}\text { NUTS II } \\
\text { District }\end{array}$ & Infested soil samples (\%) & $\begin{array}{l}\text { Pratylenchus spp./ } \\
100 \text { g soil }^{\mathrm{b}}\end{array}$ & Infected root samples $(\%)$ & $\begin{array}{l}\text { Pratylenchus spp./ } \\
10 \text { g roots }^{\mathrm{b}}\end{array}$ \\
\hline \multicolumn{5}{|l|}{ North } \\
\hline Porto & 100 & $160 \pm 150(39-456)$ & 100 & $1301 \pm 1421(88-4171)$ \\
\hline \multicolumn{5}{|l|}{ Centre } \\
\hline Aveiro & 100 & $26 \pm 16(4-45)$ & 100 & $455 \pm 503(55-1149)$ \\
\hline Castelo Branco & 100 & $15 \pm 6(11-20)$ & 50 & $510 \pm 52(473-547)$ \\
\hline Coimbra & 100 & $17 \pm 19(2-60)$ & 88 & $112 \pm 87(226-257)$ \\
\hline Guarda $^{\mathrm{c}}$ & 50 & $14 \pm 0$ & 100 & $710 \pm 0$ \\
\hline Leiria $^{c}$ & 100 & $18 \pm 0$ & 100 & $461 \pm 0$ \\
\hline \multicolumn{5}{|l|}{ Lisboa } \\
\hline Lisboa & 67 & $9 \pm 7(2-17)$ & 0 & - \\
\hline Setúbal & 100 & $12 \pm 2(11-13)$ & 100 & $67 \pm 53(16-121)$ \\
\hline \multicolumn{5}{|l|}{ Algarve } \\
\hline Faro & 40 & $16 \pm 7(11-21)$ & 60 & $6 \pm 4(2-10)$ \\
\hline
\end{tabular}

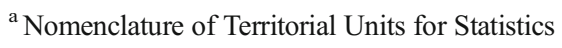

${ }^{\mathrm{b}}$ Data are means of samples/sampling site \pm standard deviation (range)

${ }^{\mathrm{c}}$ Districts where nematodes were only detected in one sample 


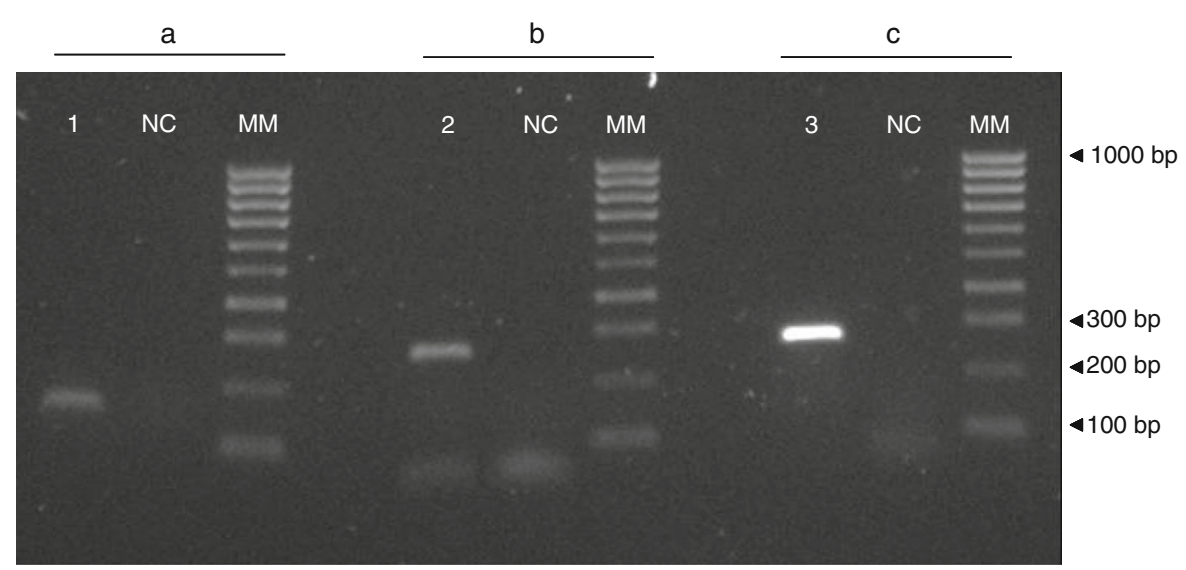

Fig. 2 PCR products of three Pratylenchus species amplified using species-specific primer sets (a- PNEG-F1/D3B5; bPPEN/D3B; c- PTHO/D3B). Lane 1- P. neglectus, lane $2-$

Four samples, of the 31 containing RLN, were negative for P. penetrans, $P$. neglectus and P. thornei when tested with the specific primers. However, a product of ca. $750 \mathrm{bp}$ was amplified using the primer set D2A/ $\mathrm{D} 3 \mathrm{~B}$, confirming the presence of nematodes belonging to the genus Pratylenchus. The comparison of the D2D3 expansion region of the 28S rDNA gene sequence of the four samples (13\%), with the Pratylenchus sequences available in GenBank nucleotide database, revealed a similarity of 98-99\% with isolate CA81 of P. crenatus (GenBank Accession No. EU130853.1). The sequences were deposited in GenBank under the accession numbers KJ493147, KJ493148, KJ493149 and KJ493150.

Root-knot nematodes were found in eight out of the 40 potato root samples $(20 \%)$ and also in $26 \%$ of the RLN root infected samples. Four distinct esterase phenotypes (single or band combinations) were detected and nine isolates identified associated with the four most common RKN species: M. arenaria, M. hapla, M. incognita and M. javanica (Fig. 3). The most prevalent RKN was $M$. incognita, with esterase phenotype I2, detected in five samples, three from Coimbra (Centre), of which one was a mix population with $M$. arenaria, A2, and two from Setúbal (Lisboa). Meloidogyne javanica (J3) was detected in two samples from Faro (Algarve), and M. hapla $(\mathrm{H} 1)$ identified in one sample from Lisboa (Lisboa) (Fig. 3). In three samples, two from Lisboa and one from Faro, the presence of egg masses was perceived, but unfortunately the population did not reproduce in the laboratory.
P. penetrans, lane 3 - P. thornei; $\mathrm{NC}$ - negative control without DNA template; MM - 100 bp DNA molecular weight ladder (Hyperladder IV, Bioline, USA)

Potato cysts were detected in $8 \%$ of the 40 root samples (33\% G. pallida, $67 \%$ G. rostochiensis) but were not found parasitizing roots infected with RKN.

\section{Discussion}

Root-lesion nematodes and RKN are among the top 10 PPN with major scientific and economic importance

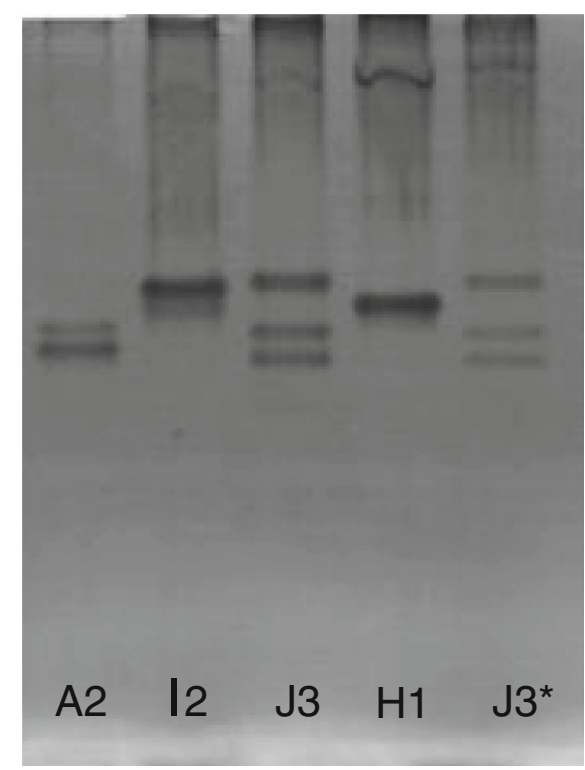

Fig. 3 Esterase phenotypes of protein homogenates from five egg-laying females of Meloidogyne spp. isolates from potato roots. A2 - M. arenaria (Coimbra), I2 - M. incognita (Coimbra), J3 M. javanica (Faro), H1 - M. hapla (Lisboa); *reference isolate 
(Jones et al. 2013). The diversity of RLN occurring in Portuguese potato fields was assessed for the first time and the predominance of Pratylenchus in the soil and root samples (33 and 31, respectively) was confirmed. RLN are known to be adapted to a wide range of soil conditions with optimum $\mathrm{pH}$ ranges varying with the host plant species (Morgan and MacLean 1968; Willis 1972). In this study, RLN were found either in very acidic soils (North and Centre regions) to slightly alkaline (Lisboa and Algarve regions), suggesting that a range of soil $\mathrm{pH}$ from 4.1 to 7.5 does not limit the development of these nematodes in potato fields. Nevertheless, all the soils showed a low or very low organic matter content. Continuous production of crops such as potatoes usually results in a rapid decline of soil organic matter because the total amount of crop residue returned to soil is low. Intensive agricultural practises like ploughing may, as well, explain the low levels. The intensive use of fertilizers could have contributed to the high concentration of available phosphorous detected in the majority of the soil samples.

Population densities of RLN in soil and roots varied between and within districts. Such variation was expected, since soil properties and cultural practices influence nematode dispersal and reproduction. In some fields, maize or beans were used in rotation with potato, whereas in others, a fallowing period followed the potato crop. For some PPN, such as PCN with a narrow host range, crop rotation fallow periods or non hosts, resistant or immune plants rotated with susceptible crops is a good management strategy, but for RLN species, with a wide host range, this strategy is not practical (Jatala and Bridge 1990). In this study, RLN populations in soil may have been also increased by the use of the rotational crops such as beans and maize, good hosts for P. neglectus and P. thornei (Di Vito et al. 2000), but the numbers of nematodes found in potato roots confirmed that RLN reproduced on potato, being an additional threat to the next crop. In three fields sampled in Porto district (North), the number of Pratylenchus in soil surpassed 200 nematodes/100 g soil. Since damage thresholds between 100 and 200 nematodes $/ 100 \mathrm{~cm}^{3}$ soil have been reported for $P$. neglectus and P. penetrans on potato (Bernard and Laughlin 1976; Olthof 1983, 1990; Umesh and Ferris 1994), it is possible that the presence of RLN may contribute to the reduced potato yields observed in Portugal. Field damage and further potato host status studies of RLN species found should be conducted. The most common
Pratylenchus species infecting potato roots was $P$. penetrans, found in $42 \%$ of the samples followed closely by $P$. neglectus (35\%). Pratylenchus crenatus and $P$. thornei were less common (13 and $3 \%$, respectively). A mixture of $P$. penetrans and $P$. thornei was detected only in one root sample from Coimbra (Centre). Pratylenchus penetrans had been previously identified from potato soil and root samples in Portugal (Abrantes et al. 1987), but P. neglectus, P. crenatus and $P$. thornei are reported for the first time as parasites of potato plants. Pratylenchus penetrans has a wide plant host range and is regarded as one of the most important RLN in western and central Europe (Castillo and Vovlas 2007). Its synergistic interaction with $V$. dahliae is known to cause tuber losses even at low population densities. Low initial densities of $P$. neglectus can also result in severe potato yield losses (Olthof 1990), whereas the presence of $P$. crenatus is often associated with apparently healthy potatoes (Kimpinski 1979; Florini et al. 1987). Pratylenchus thornei was less frequent in potato and no information is available about damage (Brodie et al. 1993).

Other PPN regarded as limiting constrains to potato production, such as RKN, were found in root samples infected with RLN. The major RKN species known to affect potatoes were found associated with this crop in Portugal (Brodie et al. 1993; Vovlas et al. 1994, 2005; Conceição et al. 2009). In order to avoid significant potato losses and RKN dissemination, effective integrated management programmes and measures to decrease the risk of spread and introduction of new RKN species are needed (Moens et al. 2009). Positive and negative competitive interactions of RLN and RKN have been reported in several plant hosts, which influences the distribution and population densities of the species involved (Castillo and Vovlas 2007). Umesh and Ferris (1994) have shown that P. neglectus and M. chitwoodi interacted competitively on potato and barley, and the outcome varied with soil temperature and host plant. Possibly, the diversity and quantity of RLN and RKN found in this study may be related to the host preferences among potato cultivars. Potato cultivars have shown different levels of tolerance to P. neglectus and P. penetrans (Bernard and Laughlin 1976; Olthof 1983; France and Brodie 1995). Concomitant infections of RKN and PCN have also been reported (Conceição et al. 2009) and may represent an additional threat to potato crops although they were not found coexisting in the present survey. Global climatic changes may lead to 
a replacement of PCN by other nematode species such as RKN or RLN. Low numbers of PCN were found in this study when compared to those of Cunha et al. (2004). We do not know the exact reason why the PCN seems to be decreasing but some hypotheses can be considered: use of nematicides in the past; recent adoption of agronomical practices by farmers, such as the use of rotation and certified/resistant seed potatoes and insufficient number of samples.

The occurrence of RLN species such as $P$. penetrans and $P$. neglectus, coexisting with sedentary endoparasites like PCN and RKN, in soils low in nutrients and organic matter, and where nematicides are not often applied may pose a substantial risk of damage to potatoes. The information obtained in this study, on cropping conditions, the ubiquity and diversity of RLN and RKN, reinforce the need for a careful monitoring of these nematodes in potato crops. Further studies will be conducted to assess the pathogenicity and damage threshold densities of Pratylenchus species on common commercially available potato cultivars such as 'Agria', 'Astérix' and 'Picasso'. Additional sampling is also required to assess the geographical distribution of Pratylenchus species, as only a few samples were collected from Lisboa and Algarve regions.

Acknowledgments This research was partially supported by FEDER funds through the Programa Operacional Factores de Competitividade (COMPETE) and national funds through Fundação para a Ciência e Tecnologia (FCT) under the project FCOMP-01-0124-FEDER-027960 (FCT PTDC/AGR-PRO/ 2510/2012). I. Esteves and C. Maleita are funded by postdoctoral fellowships financed by QREN-POPH-Typology 4.1 co financed by national funding and The European Social Fund (SFRH/BPD/68856/2010, SFRH/BPD/85736/2012, respectively). The authors would like to thank Dr. Ana Paula Ramos, Eng. João Heitor from Direcção Regional de Agricultura e Pescas do Norte (DRAPN) and Eng. Entrudo Fernandes from Direcção Regional de Agricultura e Pescas do Algarve (DRAPALG) for their support in the sampling.

\section{References}

Abrantes, I. M. de O., Faria, C. A. T., \& Santos, M. S. N. de A. (1987). Root-lesion nematodes (Pratylenchus spp.) in Portugal. Nematologia Mediterranea, 15, 375-378.

Al-Banna, L., Ploeg, A., Williamson, V., \& Kaloshian, I. (2004). Discrimination of six Pratylenchus species using PCR and species-specific primers. Journal of Nematology, 32, 142146.
Baermann, G. (1917). A simple method to recover larvae of Ancylostomus (Nematoda) from soil samples. Geneeskundig Tijdschrift voor Nederlandsch - Indie, 57, 131-137.

Bernard, E. C., \& Laughlin, C. W. (1976). Relative susceptibility of selected cultivars of potato to Pratylenchus penetrans. Journal of Nematology, 8, 239-242.

Brodie, B. B., Evans, K., \& Franco, J. (1993). Nematodes parasites of potatoes. In K. Evans, D. L. Trudgill, \& J. M. Webster (Eds.), Plant parasitic nematodes in temperate agriculture (pp. 87-132). Wallingford: CAB International.

Carrasco-Ballesteros, S., Castillo, P., Adams, B. J., \& Pérez-Artés, E. (2007). Identification of Pratylenchus thornei, the cereal and legume root-lesion nematode, based on SCAR-PCR and satellite DNA. European Journal of Plant Pathology, 118, $115-125$.

Castillo, P., \& Vovlas, N. (2007). Pratylenchus (Nematoda: Pratylenchidae): Diagnosis, biology, pathogenicity and management (Nematology monographs and perspectives). Leiden: Koninklijke Brill.

Conceição, I. L. P. M. da., Cunha, M. J. M. da., Feio, G., Correia, M., Vieira dos Santos, M. C., Abrantes, I. M. de O. (2009). Root-knot nematodes, Meloidogyne spp., on potato in Portugal. Nematology, 11, 311-313.

Cunha, M. J. M. da., Conceição, I. L. P. M. da., Abrantes, I. M. de O., Evans, K., \& Santos, M. S. N. de A. (2004). Characterization of potato cyst nematode isolates from Portugal. Nematology, 6, 55-58.

Cunha, M. J. M. da., Conceição, I. L. P. M. da., Abrantes, I. M. de O., \& Santos, M. S. N. de A. (2012). Virulence assessment of Portuguese isolates of potato cyst nematodes (Globodera spp.). Phytopathologia Mediterranea, 51, 51-68.

Instituto Nacional de Estatística, I.N.E. (2013). Estatísticas Agrícolas. Lisboa, Portugal.

De la Peña, E., Karssen, G., \& Moens, M. (2007). Distribution and diversity of root-lesion nematodes (Pratylenchus spp.) associated with Ammophila arenaria in coastal dunes of Western Europe. Nematology, 9, 881-901.

De Leij, O., Félix, M. A., Frisse, L., Nadler, S., Sternberg, P., \& Thomas, W. (1999). Molecular and morphological characterisation of two reproductively isolated species with mirrorimage anatomy (Nematoda: Cephalobidae). Nematology, 1, 591-612.

Di Vito, M., Zaccheo, G., \& Catalano, F. (2000). Effect of Pratylenchus neglectus and $P$. thornei on the growth of faba bean. Nematologia Mediterranea, 28, 261-265.

Florini, D. A., Loria, R., \& Kotcon, J. B. (1987). Influence of edaphic factors and previous crop on Pratylenchus spp., population densities in potato. Journal of Nematology, 19, 85-92.

Food and Agriculture Organization of the United Nations Statistics Division, F.A.O.S.T.A.T. (2012). Yield (ton/ha), European Union, potato. http://faostat.fao.org/site/567/DesktopDefault. aspx?PageID=567\#ancor.

France, R. A., \& Brodie, B. B. (1995). Differentiation of two New York isolates of Pratylenchus penetrans based on their reaction on potato. Journal of Nematology, 27, 339-345.

Hall, T. A. (1999). BioEdit: a user-friendly biological sequence alignment editor and analysis program for Windows 95/98/ NT. Nucleic Acids Symposium Series, 41, 95-98. 
Holgado, R., Oppen Skau, K. A., \& Magnusson, C. (2009). Field damage in potato by lesion nematode Pratylenchus penetrans, its association with tuber symptoms and its survival in storage. Nematologia Mediterranea, 37, 25-39.

Jatala, P., \& Bridge, J. (1990). Nematodes parasites of root and tuber crops. In M. Luc, R. A. Sikora, \& J. Bridge (Eds.), Plant parasitic nematodes in subtropical and tropical agriculture (pp. 137-180). Wallingford: CAB International.

Jones, J. T., Haegeman, A., Danchin, E. G. J., Guar, H. S., Helder, J., Jones, M. G. K., et al. (2013). Top 10 plant-parasitic nematodes in molecular plant pathology. Molecular Plant Pathology, 14, 946-961.

Kimpinski, J. (1979). Root-lesion nematodes in potatoes. American Potato Journal, 56, 79-86.

Maleita, C., Curtis, R., Powers, S., \& Abrantes, I. (2012a). Host status of cultivated plants to Meloidogyne hispanica. European Journal of Plant Pathology, 133, 449-460.

Maleita, C., Curtis, R., \& Abrantes, I. (2012b). Thermal requirements for the embryonic development and life cycle of Meloidogyne hispanica. Plant Pathology, 61, 1002-1010.

Moens, M., Perry, R. N., \& Starr, J. L. (2009). Meloidogyne species - a diverse group of novel and important plant parasites. In R. N. Perry, M. Moens, \& J. L. Starr (Eds.), Rootknot nematodes (pp. 1-17). Wallingford: CABI Publishing.

Morgan, G. T., \& MacLean, A. A. (1968). Influence of soil pH on an introduced population of Pratylenchus penetrans. Nematologica, 14, 311-312.

Olthof, T. H. A. (1983). Reaction of six potato cultivars to Pratylenchus penetrans. Canadian Journal of Plant Pathology, 5, 385-288.

Olthof, T. H. A. (1990). Reproduction and parasitism of Pratylenchus neglectus on potato. Journal of Nematology, 22, 303-308.

Pais, C. S., Abrantes, I. M. de O., Fernandes, M. F. M., \& Santos, M. S. N. de A. (1986). Técnica de electroforese aplicada ao estudo das enzimas dos nemátodes-dasgalhas-radiculares, Meloidogyne spp. Ciência Biológica, Ecology and Systematics, 6, 19-34.

Rowe, R. C., Riedel, R. M., \& Martin, M. J. (1985). Synergistic interactions between Verticillium dahliae and Pratylenchus penetrans in potato early dying disease. Phytopathology, 75, 412-418.

Santos, M. S. N. de A., Evans, K., Abreu, C. A., Martins, F. F., \& Abrantes, I. M. de O. (1995). A review of potato cyst nematodes in Portugal. Nematologia Mediterranea, $23,35-42$.
Širca, S., Stare, B. G., Strajnar, P., \& Urek, G. (2010). PCR-RFLP diagnostic method for identifying Globodera species in Slovenia. Phytopathologia Mediterranea, 49, 361-369.

Subbotin, S. A., Ragsdale, E. J., Mullens, T., Roberts, P. A., Mundo-Ocampo, M., \& Balwdin, J. G. (2008). A phylogenetic framework for root lesion nematodes of the genus Pratylenchus (Nematoda): Evidence from 18S and D2-D3 expansion segments of $28 \mathrm{~S}$ ribosomal RNA genes and morphological characters. Molecular Phylogenetics and Evolution, 48, 491-505.

Uehara, T., Mizukubo, T., Kushida, A., \& Momota, Y. (1998). Identification of Pratylenchus coffeae and P. loosi using specific primers for PCR amplification of ribosomal DNA. Nematologica, 44, 357-368.

Umesh, K. C., \& Ferris, H. (1994). Influence of temperature and host plant on the interaction between Pratylenchus neglectus and Meloidogyne chitwoodi. Journal of Nematology, 26, 65-71.

Van Der Sommen, A. T. C., Van Bruggen, A. S., \& Den Nijs, L. J. M. F. (2009). Survey of poorly growing patches in potato fields by helicopter. In International Congress of Tropical Nematology (40th ONTA and 28th SBN meetings), Maceió, Brazil.

Vovlas, N., Grammatikaki, G., \& Sonnino, A. (1994). Response of anther culture-derived diploid lines of potato to the root-knot nematode Meloidogyne incognita. Nematologia Mediterranea, 22, 237-240.

Vovlas, N., Mifsud, D., Landa, B. B., \& Castillo, P. (2005). Pathogenicity of the root-knot nematode Meloidogyne javanica on potato. Plant Pathology, 54, 657-664.

Waeyenberge, L., Ryss, A., Moens, M., Pinochet, J., \& Vrain, T. C. (2000). Molecular characterisation of 18 Pratylenchus species using rDNA restriction fragment length polymorphism. Nematology, 2, 135-142.

Whitehead, A. G., \& Hemming, J. R. (1965). A comparison of some quantitative methods of extracting small vermiform nematode from soil. Annals of Applied Biology, 55, 25-38.

Willis, C. B. (1972). Effects of soil pH on reproduction of Pratylenchus penetrans and forage yield of alfalfa. Journal of Nematology, 4, 291-295.

Yan, G., Smiley, R., Okubara, P., Skantar, A., Easley, S., Sheedy, J., et al. (2008). Detection and discrimination of Pratylenchus neglectus and $P$. thornei in DNA extracts from soil. Plant Disease, 92, 1480-1487.

Zhang, Z., Schwartz, S., Wagner, L., \& Miller, W. (2000). A greedy algorithm for aligning DNA sequences. Journal of Computational Biology, 7, 203-214. 